\title{
Change Management in ICU
}

\author{
Evangelia Michail Michailidou* \\ Consultant Anesthesiologist-Intensivist \\ Intensive Medicine Department, Hippokration General Hospital, Thessaloniki, Greece \\ Senior Student in the Department of Business Administration, University of Macedonia, Greece \\ Masters Degree, International Medicine -Health Crisis Management, Greece
}

*Corresponding author: Evangelia Michail Michailidou, Consultant, Anesthesiologist-Intensivist, General Hospital Hippokratio of Thessaloniki, Konstantinoupoleos 46, Thessaloniki, Greece.

To Cite This Article: Evangelia Michail Michailidou. Change Management in ICU. 2020 - 8(6). AJBSR.MS.ID.001332. DOI: 10.34297/ AJBSR.2020.08.001332.

Received: 眥April 30, 2020; Published: 眥 May 18, 2020

\begin{abstract}
Background: Change management is called any strategic action or activity that aims to exploit efficient and ancillary methods that contribute to a smooth and efficient transition of an ICU Department from an existing to a new desired state.

Objective: Continuous change is part of ICU life, but people tend to resist what is new and largely unknown. Thus, reactions and a climate of resistance within businesses are often created. A key role in managing change is played by the Director who are called upon to normalize the work environment and ensure the proper functioning of ICU Department. At the same time, the Director has the responsibility to communicate these changes to his respective teams with ICU leadership / management and to act as positive actor.

Conclusion: Any change requires the involvement of the People. ICUs need to realize that change can reach as far as the average worker can apply it at work. Employees in ICU need to take into account every individual, not just the structures and systems.
\end{abstract}

Keywords: Change Management, Managed learning, Leadership, Director, ICU

\section{Introduction}

Change is called any conversion of an existing state. (e.g. converting the work mode, converting processes, changing strategic goals and objectives of an ICU, etc.) Change management is called any strategic action or activity that aims to exploit efficient and ancillary methods that contribute to a smooth and efficient transition of an ICU Department from an existing to a new desired state.

a. Strategic changes - are the changes that refer to the strategic direction of an ICU (e.g. mergers, change of institutional role, change of ICU, etc.)

b. Functional changes - affect the way the various business processes are conducted (computerization, trading systems, and citizen service, etc.)

c. Functional changes - affect the way the various business processes are conducted (computerization, trading systems, and citizen service, etc.) d. Changes in culture - they affect the basic ICU's philosophy and culture of an ICU as well as the way and quality of work (e.g. installation of systems and mechanisms of CQI - Continuous Quality Improvement - Continuous improvement Quality

Need for change - The need for change is often obvious when for example the results are not as expected. People by nature do not want failure because it contains the risk of shame, diminishing the image of others, and lack of respect. We expect leaders to be capable, and to accomplish things in the right way. Managerial missteps - breaking agreements and failing to regain confidence -the excessive promotion of the positive elements of change and the lack of awareness of the negative issues associated with it -the manager's uncertainty or doubt about the change affects their ability to lead the implementation effort -when managers interrupt accepted practices or values or principles, or even suggest their insignificance and importance and use their alternative approaches [1]. 
It is be use to identified four general reasons that indicate the need and define planning for methodical change:

I. To promote the humanitarian character of work

II. To contribute to employee and patient satisfaction and social well-being

III. Improve the means to meet the financial needs of individuals

IV. Increase in profit

\section{Definition of Leadership}

Leadership is defined as "Influencing the behavior of members of a social ICU to tend toward the effective fulfillment of its goals. Behavioral influence is achieved based on the will of individuals and not by coercion (Burandas, 2004).

a. Hold everyone accountable (The change leader must signal that enterprise-wide transformation will be a collective effort, with accountability distributed throughout the ICU).

b. Invest in new ICU capabilities (Change leaders must go beyond storytelling, motivation, and mobilization efforts-they need to provide resources so that the ICU has what it needs to win in the new environment. This might include capital improvements, process improvements, and building new talent capabilities).

c. Emphasize continuous learning (It's far easier to talk about revitalization and renewal than to do it. The companies that pull it off have transformation leaders that commit to a relentless learning process).

What is ICU Development? The process used to enhance and enhance both the effectiveness of the ICU and the quality of life of its members through designed interventions? (Figure 1) [2].

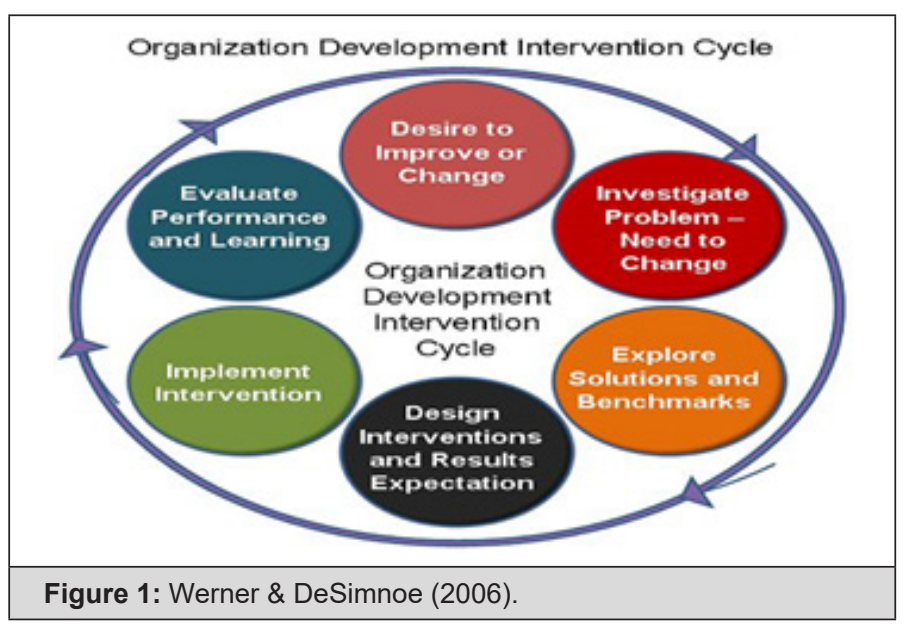

Human resource restructuring by the Director, as well as expansion of activities, diversification of strategic direction and goals. Previous are some indicative changes - small or large - that the ICU Department can proceed to meet the challenges of the progress. Continuous change is part of ICU life, but people tend to resist what is new and largely unknown. Thus, reactions and a climate of resistance within businesses are often created. A key role in managing change is played by the Director who are called upon to normalize the work environment and ensure the proper functioning of ICU Department. At the same time, the Director has the responsibility to communicate these changes to his respective teams with ICU leadership/management and to act as positive actor. ICU culture, that is, the set of values shared by members of an ICU, is particularly important as it is directly related to the financial results and the sustainability of the ICUs. At the same time, each ICU is faced with changes in its internal and external environment and is urged to recognize in a timely manner the need for change and adopt appropriate action plans in order to take the lead in securing and maintaining a comparative advantage. In an ever-changing and competitive environment, businesses have to constantly adapt to new data in order to remain competitive and sustainable. As a result, a set of forces pushes ICUs to make changes. Undoubtedly, effective change management reduces perceived resistance by building trust and giving people the courage to take the first step in the right direction and then move forward with strength and courage, notes Herman Miller. But the most important thing is to build mechanisms for adopting change and to develop corresponding skills so that the next change is easier when it happens. In addition, every ICU change also brings about a change in ICU culture. The concept of change management is familiar to most businesses today. However, the way each ICU manages change and how successfully it does vary as it depends on the nature of the ICU's activities, the type of change and, ultimately, the people involved. Change management is essentially the implementation of a structured process and corresponding tools designed to enable individuals or groups to move from an existing situation to a future one in order to achieve the desired outcome [3].

«Unfreeze, Change, Refreeze» At the same time, as illustrated by the theory of Kurt Lewis, recognized as the founder of social psychology, in a business there is a dynamic of internal tendencies that affects its functioning. In the field of dynamic field analysis, as it is called, in an ICU there are some forces that lead to change or resistance. In particular, any ICU that plans to change has those forces that are in favor of change and those that are against it. In practice, this means that those who have a strategic role in planning and implementing any change must strengthen the forces for change and weaken the forces that resist it. In the first case, creating a positive climate and the leader's own vision (either of the whole ICU or the team) can make a positive contribution to the change. On the contrary, complex processes, unclear message and introversion combined with lack of structure can enhance resistance forces rather than bend it (Figure 2). 


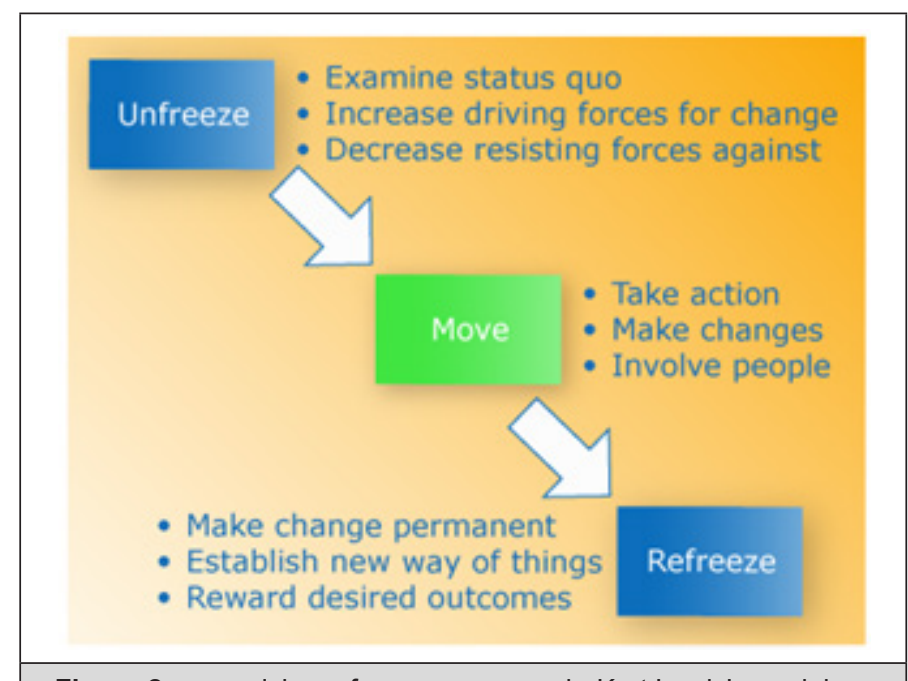

Figure 2: www.alchemyformanagers.co.uk- Kurt Lewis's model.

According to Kurt Lewis's model, ICU change is a process that goes through three stages. Initially, it is the stage of the "Unfreeze" in which the existing situation is disrupted and the gap between the existing situation and the desired one becomes apparent. The result is a review of what is happening so far and an understanding of the need for any type of change.

Then comes the "change" which is essentially that transitional period until the change comes. Many times, at this stage, everything that has happened so far is called into question. Stakeholders are invited to adopt new codes of conduct and codes of conduct. At the same time, new structures, systems and processes can be established. As can be seen, all of the above "shake" executives out of their position and the so-called "comfort zone" and can create tensions and a disturbing climate. In the end, there is the "freeze" (refreeze), that is, re-engagement into a new order of things. Here, it has taken shape and the change - small or large - has begun to take shape, with the result that the calm and smooth flow of business returns. This is achieved through ways such as communication, rewarding success, commitment to leadership, and appropriate training. What is crucial for ICU Departments, according to K. Lewis's model, is homeostasis, that is, the tendency that an ICU Department brings when it experiences a change to return to its original equilibrium, to its original state of affairs. He therefore suggests that this balance point must be moved elsewhere (defrostchange) and then firmly stabilized (change-re-freeze) in order for ICU change to succeed [4].

Change \& Transformation Change means a process from an existing situation, point $\mathrm{A}$, to a future situation, point $\mathrm{B}$, framed by external or internal factors. Many times, the notion of change is identical or simply related to the term of transformation. According to an article in the Harvard Business Review, change management means the implementation of finite initiatives, which may concern the whole or part of the ICU. The focus center shifts to perform these changes in a clearly defined way. For example, if a large-scale tech ICU incorporates specialized engineers into its regional sales teams, then there will be changes in roles, in client coverage, in sales targeting and in teamwork. Inevitably, a whole bunch of people are affected.

Here, if the principles of change management and corresponding tools are applied, such as: the new framework of work, the creation of good relationships between Managers, the involvement of all stakeholders and the value of discipline, then the ICU's new sales approach is going to be successful and is mainly going to produce improved financial results [5].

On the other hand, as noted in the same article, thetransformation is quite different. Unlike managing change, transformation does not focus on some specific, clearly defined changes, but on a portfolio of initiatives that are either interdependent or intersecting. The most important (alert) difference is that the ultimate goal of a transformation is not to make a change, but to rediscover the ICU itself and to revise the existing operating model based on the vision for the future. Beyond any doubt, it implies a much greater risk as a condition than anything else as it is unpredictable what will happen or even experimental. Indeed, as emphasized, even if a change is deemed successful in the context of total transformation, the process itself can fail.

Analysis in... internal terms However, in order for ICU change and/or transformation to be designed, implemented and ultimately implemented successfully, businesses must clearly define the goals they want to achieve through the implementation of change and set out in detail the areas in which these goals are focused. As "companies" analyze their external environment in order to determine their strategic path and set goals, it is equally important to carry out an internal analysis to reveal their strengths and weaknesses within the ICU. In the case of ICU change, it is even more necessary to clarify the points that will help to achieve the goals of ICU change, but above all, what is going to work the opposite way and to agitate the climate.

Above and identifying opportunities and threats presented can guide the way around both the changes that need to be made and the way they can be approached and implemented. At the same time, a methodology for managing change is a strategic reference point for successful change. It concerns a structured set of steps around designing and implementing ICU change. As with other methodologies, e.g. of Project Management, Change Management provides a consistent framework for decision-making and guides the actions of managers, in our case the actions of ICU Director. In the context of ICU change, this model allows leaders and teams responsible for change management to focus their activities on what will act as a driving force primarily at the individual level and then on the results for the ICU. In addition, it provides a simple, easy-to-use framework for each executive individually to think about change. 
Ultimately, change is a common thread found throughout the business of whatever size, location and age. The world, after all, is changing so fast, and so must ICUs. Undoubtedly, the ICUs that manage change will prosper and grow while the rest will struggle to survive.

\section{Tips for Successful Change! - For a successful change employees in ICU can apply the following}

\section{Set the expectation of Change as inevitable}

Many times a change ends up inexorably because employees themselves have their own tacit expectations. If employees of the ICU have fallen into the trap of assuming that their working environment will always be stable and comfortable and in which they will have a stable location, next to their colleagues, referring to the same Manager, then they are more likely to feel " blind "and out of reality when the smallest possible change such as the reference structure occurs. It is clearly not possible for the ICU to be able to control how their executives feel and / or share stories. But one can communicate on a continuous basis the ICU's vision as a dynamic and changing ICU, in which progress and change inevitably intertwine. In fact, if the employee receives this message from the beginning (the recruitment process) and is then reinforced through the meetings, it can prevent the team members from being complacent or assuming that they are working in a static environment. Thus, when a crucial change occurs, they are more likely to receive it positively and smoothly. Even spatial change could be an introductory change aimed at enhancing culture in this direction.

\section{Understand "How will I be affected?"}

A change can be as positive and negative as the results it brings. For example, it may relocate to new building sites due to overall growth (positive change) or it may relate to staff reductions to meet its financial requirements (negative change) Whenever there is a significant evolution in the work environment, a decline in productivity of executives at the individual and team level can be observed in response to a new paradigm, environment, ICU structure or even team leadership. The point that will make the difference is the communication message from the ICU. The 'What is happening here is' this' and employees in ICU can do' that 'approach will create resistance or enhance the existing one. In contrast, the ICU must "wear the shoes" of its executives and give them the space and time for any adjustment. One universally sound approach is to put the message: "There is a change and we know employees in ICU are going to have questions. We are here to discuss them and talk about what concerns them."

\section{Identify the Key players}

As people respond differently to changes in the workplace, the Manager/Leader is responsible for identifying those executives who will play the role of ambassador as well as those who can sabotage any effort. Key players, then, are the executives who will lead and be called upon to manage the process of change within a wider system of people and dynamic relationships. It is crucial for Key players to "embark" from the beginning of the journey of change and to be prepared to "travel" and "reach their final destination" under any condition, with the rest of the members being involved. Each member of an ICU, from any hierarchical rank can be a Key Player to one degree.

\section{Embrace the Challenge/Overtake the status quo}

Then, and based on the culture of change, it is essential that the Leader or Manager of a ICU or group share the challenges that the ICU faces with other members openly. Assuming that a challenge is not communicated openly and Leader launches a major administrative change, are employees more likely to think that Leader himself is acting in a whim or reckless manner and triggering non-positive reactions? From this point of view, then how else would employees be aware of the challenges that exist in responding to any change if someone has not shared it with them?

At a time when change is the only certainty, ICUs are urged to respond quickly and successfully to rapidly changing external and internal environments. However, the percentage of ICUs that manage change successfully remains low.

In order for change management techniques to achieve the desired effect, we first need to understand that a change in mindset is needed, not just actions. Change Management is a way of thinking and attitude. It defines the business function and is the methodology and logic through which we are driven to adapt to new data rapidly and flexibly.

While designing and implementing any change requires "courage" from the Management side, adopting the change requires employee confidence. Leadership groups that do not regard the human factor as important - as it is the people who will be called upon to work and perform in the new emerging environment - are, in mathematical precision, always at the forefront of failing to make any change. It is important to understand that precisely because change management is identified with the culture of the ICU, there is no common methodology for all ICUs. However, there are a number of practices and tools that can help create that environment that will make it easier for people to adapt quickly, depending on the circumstances. Change Management culture is shaped in every ICU by the leadership team whose commitment and flexibility are the most critical factor in the success of the Critical Success Factor. The leaders of ICUs in this new era must be agents of Change (Agents) and carry the agility philosophy throughout the ICU. Managing change is a big bet for companies that most often start off with buzz and drumming from management and end up with less time for a real change that brings tangible results and growth. It is well known that $70 \%$ of change initiatives fail, mainly due to employee resistance and lack of support from management [4-7]. 
The vision, strategy, values, ICU structure, goals, policies and processes may be there, fully implemented and skillfully communicated, but that is not enough. It goes without saying that the above should already have been set up to begin the main task of managing change. Unfortunately, when a ICU has reached this stage, it believes that much of the work that needs to be done to implement a change has been achieved. The essence, however, is continuity. What are its actions on employees' beliefs on the values that govern their day-to-day operations, on traditions that hold captive behaviors and functions, on unwritten laws that are often more powerful than any ICU value. And even more profoundly, how the Director copes with the many feelings that emerge while managing change for each employee.

Helping to manage change can be our digital age. Although companies are increasingly using digital tools to attract customers, deal with complaints, promote products, and so on, their use of change management still seems to be quite limited.

But if we envision a ICU using digital tools to make the change management experience more personal by individually showing what the employee's contribution is to achieving it, using gamification tools, creating online forums and contests to enhance empathy and meaning. community, if it implements digital tools that will show the overall progress of the change so that employees can see what is happening in real time rather than on a quarterly basis reporting, then maybe managing change can be more painlessly done and employees turning from mere observers to ambassadors of change. Now operating in an ever-changing business environment, driven by unstoppable socio-economic and political change, the business world is called upon to change its mindset and attitude towards change. The digital world can become a competitive advantage in managing change.

We live in times of high liquidity. Everything is constantly changing, with ever increasing rates. Change is here to stay. But is this necessarily bad? Isn't change an integral part of our lives? There is nothing static in this world. Change = life. From the moment we are created to the moment we die, we are constantly transformed. When stagnation occurs, death occurs. So ICU Departments, a system of people, relationships, and interactions, are alive. As such they are therefore changing. Time to time. That in itself is a huge challenge. Because change creates (or offers, depending on how one sees it) "problems". Problems that a "smart ICU" must see as opportunities for improvement. Even the conscious decision not to take any action is a decision. That too will create a new treaty.

In this perpetual life cycle of any ICU, the principles that govern successful change management are perhaps extremely simple, but so fundamental:

a. Acceptance of change in a supportive context that understands the instinctual resistance to change b. Making quality decisions from the right groups

c. Timely implementation of decisions, being ahead of events and not after them

d. Coordinated communication at all levels that clarifies the "why" of the decision and gives the vision of the new situation after the change.

"Wearing the hat of the coordinator", mentor, moderator, mediator, team leader, we are called upon to support the ICU in turning the vision of change into clear steps, ensuring - as far as possible - that the moves are made in the right time. at the appropriate pace, taking into account all the dynamics of the ICU system. Daring to give a fairly general definition we could say that ICU change is the transition from one state of affairs to another or otherwise the transition from a given set of conditions to a different one (Houtiris, 2001). Elliott (1990) defines change as a complex psychological event. For half a century, many studies and articles have been published trying to identify those contributing to the success or failure of ICU Change.

The three truths about ICU Change are:

Truth \# 1: ICUs cannot change faster than the people who make them change.

Truth \# 2: It succeeds or fails depending on the conditions in the ICU.

Truth \# 3: To achieve change in the ICU, one needs to change its culture first.

But how is the culture of an ICU affected by a small and / or major change?

Every ICU has and definitely has certain characteristics that make it stand out and compose its culture. Changing an ICU means changing its culture, and conversely, changing its culture also results in changing the system itself. ICU culture is difficult to change but not impossible. When we talk about change in ICU or culture we mean real changes in people's behavior throughout the ICU. Peter Senge argues that in order to create and maintain a profound change it is vital to temporarily suspend our mental models and patterns and possibly change them. But how should an ICU really handle the change effort? It takes a lot of time, effort, resources and continuous effort to change a situation in an ICU. So there are no recipes and secrets. Any change requires the involvement of the People. ICUs need to realize that change can reach as far as the average worker can apply it at work. Employees in ICU need to take into account every individual, not just the structures and systems.

\section{References}

1. The Definitive Management Ideas of the Year from Harvard Business Review (with bonus article "How CEOs Manage Time" by Michael E. Porter and Nitin Nohria, 2020): 1090BN-BUN-ENG 
2. (2014) Managing change: a strategic approach to organizational dynamics By Bernard Burns Harlow: Pearson Education Limited.

3. Peter Senge popularized the concept, "Learning organization" in his book, "The Fifth Discipline-Art and Practice of the Learning Organization: Random House Business Books.

4. Kotter, John P (1999) On What Leaders Really Do.
5. Kotter, John P (2016) That's Not How We Do It Here!: A Story about How Organizations Rise and Fall and Can Rise Again p.176.

6. https://www.ukessays.com/essays/business/kotter-and-lewinschange-and-positive-models-business-essay.php?vref=1

7. (2007) Harvard business review hbr.org the tests of a leader. 